\title{
African Researchers and the Rural School Issues in South Africa: A Predatory Culture
}

\author{
Mpho Dichaba \\ College of Education, University of South Africa, South Africa \\ E-mail: dichamm@unisa.ac.za \\ Monde Ndandani \\ Department of Basic Education, South Africa \\ E-Mail: Ndandani.M@dbe.gov.za
}

\section{Doi:10.5901/mjss.2013.v4n14p397}

\section{Abstract}

One of the mandates of Comprehensive Rural Development Programme (CRDP) in South Africa is to ensure that all schools and health facilities have access to basic infrastructure such as water and electricity by 2014. Our academic researchers have not researched much about how rural schools that do not have infrastructure have been managing to achieve school education outcomes. When wind-storms occur (sometimes accompanied by rains) learners coming from the same rural regions of our country do not go to school to avoid the risk of having their classroom roofs and walls collapsing on them. Our statistics show an entry of rural mud-walled schools, especially in the Eastern Cape Province in 2011. This paper confronts these challenges of South Africa's rural schools in 2012 and 12 years (k-12) in the future of our rural schools and their learners.

Keywords: Rural schools, Annual National Assessment, feasible partnerships, African researchers

\section{Introduction}

Thinking beyond the $21^{\text {st }}$ century with South Africa's history of rural schools and schooling in mind creates frustration. General and specific conditions of our rural schools and schooling put these schools in context of $19^{\text {th }}$ if not $18^{\text {th }}$ century in the history of education in this country. In Entshingeni village, in the Eastern Cape province of South Africa, a mud hut with a dirt floor serves as a classroom to 79 grades 1 and 2 learners who sit on planks across rickety bench frames in front of a battered chalkboard (Sowetan 25 June 2012). Recent Annual National Assessment (ANA) report by Motshekga (2011) of children in Grades 3 and 6, who simply cannot read and write at their Grade-level, refer to a "big" number of children from our rural primary schools.

Investment in "wind energy" and a "greener tomorrow" in the context of school education in our rural regions and their learners would be a classical example of those among academics and academic researchers who are tickled by being esoteric. The interesting observation is that learners in these schools know about construction of cooking places outside huts or houses to protect cooking fire and pots from strong-blowing wind with its dust that it always carries in these rural regions. If winds are "strong" where do they get their "strength"? (Geography lessons at Foundation and Intermediate Phases indicate that "winds blow from high pressure belts to low pressure belts"). What is the difference between strong-blowing wind and morning breeze explained as "any wind blowing between 4 and 31 miles per hour"? Further still, these children in our rural schools know about wind-mills. They know that wind-mills are erected to pump out underground water for use by people, farm animals and for watering food crops. They also know that it uses a still structure with a winged wheel on top to pump water. The gap we are expected to close here as teachers, is between the wind-mill and wind turbine and the uses of these two structures both using wind.

According to the Fossil Fuel Foundation of Africa, from "wind" to the staple food of the rural folks we are informed that South Africa, like many other nations of the world, is becoming more conscious of the so called "green" issues, particularly greenhouse gasses and global warming. Fossil Fuel Foundation of Africa further explains that:

In order to try and reduce her emissions of the so called greenhouse gasses, South Africa is investing heavily in other alternative, sustainable sources of energy. Her latest initiative is to the production of biodiesel and bio-ethanol both of which are produced from maize crops. The South African government is now offering large incentives to farmers for converting their crop cultivation over to maize. It is seen that many thousands of new jobs could be created in the 
cultivation, harvesting and processing of maize into bio-fuels. This would not only be great news for their own internal economy as regards employment figures, but it would also substantially reduce South Africa's dependence on crude oil both internally mined off-shore, and also imported from foreign countries (www.fossilfuel.co.za).

The curriculum and sometimes the language of instruction are not suited to local conditions (Atchoarena \& Gasperini (2003). For instance, the value-chain of maize that our rural school learners are familiar with is that maize is their staple food. This includes food such as green mealies (roasted or cooked), green mealies mixed with fresh beans, mealies stamped to samp, maize meal for steamed "pap" and porridge, and maize meal for steamed bread. Here is another gap that our education provisioning for our rural regions has to close-between samp and bio-ethanol. One of the vital considerations in the context of rural life is that it is featured by generic poverty which accounts for a small number of learners accessing tertiary education. This leaves most of these learners still having to earn or scratch a living in their rural environment even after completing grade 12. Education here should provide skills to produce maize to feed people. It also has to allow people to come up with ideas to advance education. In this case people could process maize to produce biodiesel that would be something ludicrous, to say the least.

The curriculum and sometimes the language of instruction are not suited to local conditions (Atchoarena \& Gasperini (2003). For instance, the value-chain of maize that our rural school learners are familiar with is that maize is their staple food. This includes food such as green mealies (roasted or cooked), green mealies mixed with fresh beans, mealies stamped to samp, maize meal for steamed "pap" and porridge, and maize meal for steamed bread. Here is another gap that our education provisioning for our rural regions has to close-between samp and bio-ethanol. One of the vital considerations in the context of rural life is that it is featured by generic poverty which accounts for a small number of learners accessing tertiary education. This leaves most of these learners still having to earn or scratch a living in their rural environment even after completing grade 12. Education here should provide skills to produce maize to feed people. It also has to allow people to come up with ideas to advance education. In this case people could process maize to produce biodiesel that would be something ludicrous, to say the least.

Dolny (2011) tells his readers that Facebook started over 7 years ago. He also mentioned that today Facebook has over 500 million active users and that almost all South Africans have cellphones. Dolny (2011) knows that an infinitesimal percentage of rural folks and its learners have cellphones, more so that in some of these rural areas there is no reception for cellphone calls. David Amanor, a BBC correspondent in Ghana, writing in Focus on Africa (JulySeptember 2011) about the value of e-reader for Ghana rural schools, says the e-reader displays text in a digital format and can hold up to 3,500 e-books at any one time. The books are downloaded by a cable attached to a computer or directly from online retailers using a built-in wireless receiver. Even when our rural primary school learners can access these devices (e-readers), the "big" problem is that the majority of these learners can hardly read.

\section{Environment and Learning}

Jean Piaget's unique studies with children inform, among others, that cognitive development results from the interactions of individuals with their physical and social environments. Thus, developing and shaping their schemata. According to Piaget, people interact with their environment through two unchanging processes known as assimilation and accommodation. Assimilation is a process whereby an individual interacts with an object or event in a way that is consistent with an existing schema. Accommodation is a process whereby an individual modifies an existing schema to account for a new event. Assimilation and accommodation are two complementary processes. Thus, on the one hand, assimilation involves modifying one's perception of the environment to fit the schema. On the other hand, accommodation involves modifying the schema to fit the environment. Educational efforts in our curricular policies and documents should be focused on how learners in rural environments should positively adapt to such environments. Education projections, incorporating future plans for our children in rural community schools should consequently have environmental adaptation among their foci.

\section{Fake Concerns/Avant-Garde Academic Posturing}

Everybody including learners and teachers know conditions in the rural schools. Academic researchers, especially the black and African, have no moral excuse for not having even the finer details of the day-to-day conditions of learning and teaching in these schools. Since we have all known about these conditions for over half a century, at least those in institutions of learning who are around 50 years of age, the question that embarrassingly faces all of us who know is: What have we done with this "knowing"? Peter Reason and William (2011) Torbet wrote as follows: 
Because human beings are all participating actors in the world, the purpose of inquiry is not simply or even primarily to contribute to the fund of knowledge in a field... but rather to forge a more direct link between intellectual knowledge and moment-to-moment personal and social action, so that inquiry contributes directly to the flourishing of human persons, their communities, and the ecosystems of which they are a part (Kincheloe, and Mclaren, in Denzin, and Lincoln, 2005:314).

There has not been much of flourishing of rural schools resulting from our research and conference papers. Under sub-heading "Action research and change", Gray (2009) points that, in addressing real world problems, the action researcher becomes directly involved in the research process as a change agent, devoted not only to studying organisations and processes but also to improving them. Gray (2009) relates that the term "action research" was first coined by Lewin, in 1946, by which he meant a process through which theory building and research on practical problems should be combined. Academics in general and academic researchers in particular, are indicted here as Chambers (1983:33) puts it:

So while academics seek problems and criticise, practitioners seek opportunities and act. Academics look for what has gone wrong, practitioners for what might go right.

Research projects and conference papers take years going from one referee to the other to be scrutinized for formalistic requirements. And potential readers engage with the findings and recommendations of these research and conference papers when they have gotten stale beside unnecessarily delaying the possible implementation of their recommendations. Ornstein (1978:5) has ruled on this formalism when he maintained:

\begin{abstract}
Careful research and impressive designs and analysis, however well received by the researcher's peers, rarely have any impact on school personnel, and though high-quality research standards may indeed be proper measure of scientific progress, they are not necessarily the ideal way of advancing educational progress...Most contemporary criticism of the research community in education is directed not at its effectiveness in advancing knowledge, which is now taken for granted, but at its lack of capacity to couple knowledge to action, to project knowledge into the practitioner's arena, and to produce insights relevant to the solution of the real problems that exist in classrooms and schools.
\end{abstract}

\title{
4. Literature Review
}

On Tuesday, 9 August (Women's Day in the New South Africa) 2011, SABC's TV station 2 showed a programme on women in one of the villages around the town of Ngqeleni/Mqanduli in the Eastern Cape Province. These women were working on a gravel road using spades and wheelbarrows. One of the women interviewed by one SABC journalist said the reason why they were working on this road was to repair it because when it rains the children of their village cannot use it when they walk to school. Vehicles that drive through this road dare not do that when it rains as it becomes more unsafe. Hence, even those children who may have transport money would not have transport to carry them to school driving through this road. Hence, children in this village do not go to school when it rains.

In Taung in the North-West province of South Africa, when children go to school during flood rains, they drown. The South African Schools Act, 84 of 1996 says that any parent or guardian who does not ensure that children between ages of seven and fifteen years under their care or custody attend school, that parent or guardian will be subjected to the punitive measures provided by this law. On paper, all our children must be at school whether school transport is provided or not. Before anybody engages with what goes on in the school yards and classrooms, children must reach school reach school in time and safely. Therefore, in the context of this paper, these are schools in the remote rural villages of South Africa.

In the Eastern Cape province of South Africa it was reported, on 17 February 2011, that because of funding crisis the learner transport programme was stopped in January 2011, leaving more than 100000 learners without transport to school. The Eastern Cape Department of Education reported that it needed R247 million to pay service providers, and had only raised R60 million. Consequently, many learners started walking long distances to school in the heavy rains the province was experiencing (WWMP). In the Taung region of the North-West Province learners risk being drowned if they walk to school in the heavy rains. In a significant number of rural areas of the former Transkei area of the Eastern Cape province and some areas of KwaZulu-Natal (e.g. Ixopo, High Flats, Richmond in the south; and Ndwedwe, Maphumulo, Mantobela and north of Richards Bay in the north), there are schools located in inaccessible places even if the respective provincial governments can successfully provide school transport. In such places no vehicle would drive around to pick 
up learners and transport them to these schools in this bad weather conditions. They are also not likely to make it in time for the morning assembly.

Ganyesa and Morokweng region of the southern part of the North-West province in South Africa have some schools located in areas with such conditions (Bona-bona and Madinonyana areas are typical examples). Issues of facebook, twittering and e-learning will be dealt with when children of our rural communities are inside their classrooms. It is the view of this paper that on a significant number of educational research areas, black and African researchers in the education sector, in particular, need to relook into their use of the secondary data. Gray (2009:497) says:

It is important to recognize that researchers can have access to data in the form of documents and other resources where the data has been collected by others. For qualitative researchers secondary data analysis involves the analysis of another researcher's qualitative data or documents.

A number of black researchers in education have their homes in the rural villages of South Africa and yet frequently use secondary data on schools in their home villages. They also use secondary data of other villages in their neighbourhoods in their scanty research articles. On the News24 (2010) it was reported that according to the Department of Basic Education's document presented at a symposium in Pretoria a total of 400 schools in South Africa are built of mud. A subsequent Action Plan 2014 also indicated that currently 1700 schools had no water and 700 had no toilets. It also points out that the estimated shortfall of 63000 classrooms and the fact that 15000 schools still have no library is a call for action that goes beyond the medium term.

It is obvious that all the 400 mud schools and the schools without toilets are in the rural communities of South Africa. The big number of the 15000 schools that do not have libraries is also of rural schools. This report is dated 28 October 2010, meaning that for 15 years since 1995, a year after our democratic government took over from the apartheid government of the National Party, we still have approximately 700 rural schools with approximately 350000 children (assuming that the average enrollment in each of the 700 schools is 500) without toilets. When you multiply 15 000 schools by 500 learners in each of these, you get a total of 7, 5 million learners in our rural schools with no libraries. Also, when you multiply 1700 (rural) schools by 500 (learners), you get a total of 850000 learners with no water between 07:00 and 14:00 from Monday to Friday of all school days. Add on this the physical and social environment impact on learning and learning activities (refer to Piaget's cognitive development of children [at school]).

It's common knowledge that both newly qualified teachers and teachers with more than 5-10 years teaching experience do not want teaching posts in rural schools where there is shortage of Mathematics and Physical Science teachers. And we have everybody aspiring that, irrespective of the schools learners attend, they should be strong in Mathematics and Physical Science. Van der Berg (2008) supported this statement when he indicated that poor schools experience resource combination challenge in that over and above material resources, good teachers normally avoid working in them. If these schools do not have libraries, chances are close to zero that they will have laboratories for their Biology and Physical Science experiments. In this case, educators have a challenge of implementing self-discovery learning approach due to the lack of libraries, laboratories and other resources through which active participation by learners can be ensured (Gray 1997: 3). Without belabouring the point, all South Africans know that schools that do not have electricity and telephone lines do not even worry much about not having computers and television sets that have educational programmes of one kind or the other. The main point of this paper is that research and researchers, especially researchers who were born and bred in any rural community of South Africa, should not continue marginalising or worse still, ignoring our rural learners and their learning. They need to also focus on these communities when doing their research. Research and researchers, as and when this academic exercise or activity and its implementers focus on the plight of our learners in the rural regions of our country, let the reminder of Mugo, MG ( in Makgoba 1999:212) ring loud and clear. He writes:

We have talked and talked about education and culture until our words have turned into static verbs in our mouths, quite devoid of action. We have heard others speak, just remaining sufficiently awake to hear the end of their speeches before yawning with relief... Soon, very soon we will be talking to ourselves because there will be no one listening...

Now, it is our responsibility to start working, interrogating our inaction, and jogging our evasive collective conscience. We know what needs to be done and must start doing something about it before the situation becomes worse to a point of complete collapse of rural schools. 


\section{The Task of Doing}

The problem of rural schools is a global and multi-dimensional one. Although, it is more pronounced in the Third World countries than in the Western European countries, North America, Australia and Japan (collectively referred to as First World countries). Even Stevens and Wood (1992:31) do not render this problem to be less of a problem when they explain thus:

\section{...equality of educational opportunity implies, not merely 'equal' schools, but equally effective schools, whose influence will overcome the differences in starting point of children from different social groups.}

Gray (2009) provides an entry point for 'the task of doing' in his explanation of a research process as a practical one. Firstly, you identify a problem, decide how to tackle it, collect data, analyse and present findings. Finally, you act on the findings. Decisions to tackle the problem of rural schools in South Africa during the first quarter of the $21^{\text {st }}$ century (the time period up to 2025) are expected to vary from one researcher or group of researchers to another. The Action Plan 2014 of the Department of Basic Education should not be the only road map to the solution of the problem of our rural schools and rural schooling. Even within our present government, rural and remote rural schools problem should be the matter of interdepartmental collaboration. This is the problem primarily for all of us in the education sector, especially those of us claiming to be budding or experienced education researchers having been born and bred in one rural village or the other here in South Africa.

Van der Berg (2006:18) maintains that research has widely accepted that lack of resources hampers effective teaching and learning. One of the easiest things to do by anybody concerned about equal quality education for all children in our country is to report corrupt people to relevant authorities. If these people are not reported, they will continue to disadvantage our children in any manner or take away from them anything that is meant to help with their learning and their schooling. On 17 February 2011, Lynn Taylor reported in the WWMP media website as follows:

The School Nutrition Programme in the Eastern Cape has been stopped due to lack of funds, despite huge underspending in previous years. Tens of thousands (of learners) are going hungry (in these schools).

Adults, some of them within the education sector, taking away South Africans' tax money that is budgeted to provide meals for children at our schools, should be criticised through all types of our available media. Late, and worse still, non-delivery of stationery and other learning materials to all our schools should be subjected to the same treatment. This delivery and these items are also provided by our tax money as well, hence when our hard-earned money is not used for what it is meant to be used for, then we need to complain and report it.

\section{A Pair of Scissors and a Newspaper}

Not all rural schools receive free books and reading materials from organisations such as Read. Currently, we have 7.5 million learners without access to a library. And chances are that in 2014 we may not see any building foundations and bookshelves in place, let alone books and reading materials themselves. However, our concern with reading materials, including children's books and comics, books in general, magazines, journals, is that they must be foregrounded by inculcating reading enthusiasm in learners from lower grades to all exit classes of all educational institutions. It is hence, the researchers' function to unravel the relationship between these two variables: reading materials and reading. Of equal importance here is the matter of the language of the reading materials themselves. This, in turn, is the function of teachers in all our schools and classrooms of learners in all their grades and levels of their education process.

\section{Rural Folks Taking Ownership of Their Children's Schools}

The School Governing Body (SGB) informs the parent body and other people featuring in the affairs of the school that schools are basically the responsibility of the provincial government. However, as a number of these rural schools are built of mud bricks do not have electricity, water, toilets and telephones; it is the responsibility of the SGB to inform the parents of children who attend at these schools that their children use these schools. And therefore they, the parents and other members of the respective communities, must work together to improve conditions of these schools, while waiting for the provincial departments of education in collaboration with departments of public works to bring such schools to the required standards of all schools in the country. This parents' working together includes repairing classrooms, school 
fencing, maintaining the school premises and providing security for the school and its available assets. To get these parents commit to working with teachers in schools like these requires that teachers in these schools, must also do their best to turn these schools into homes away from homes for the learners because government take a long time to respond to the schools' needs. The SGB should encourage these teachers to dedicate themselves to their work like they would do when they do things for their homes.

\section{Feasible Partnerships to Advance the Cause of Rural Schools}

David Amanor's story with Presbyterian Junior High School in Adeiso, a rural town in Ghana's Eastern Region (Focus in Africa. July-September 2011) is rare in the general scenario of rural schools in South African provinces that are themselves predominantly rural in South Africa. Amanor (2011) reports that the e-reader trials in Ghana are being conducted and funded by Worldreader.org, a non-profit organisation. In South Africa we have had Microsoft Africa, but getting to our remote rural schools with its hardware and software has, so far, not registered any noticeable presence. Apart from igniting children's love for reading, one of the e-reader project's aims is to convince governments in Ghana and other developing countries that there is a technology hop to be exploited which could swiftly improve literacy and revolutionise education (Amanor, 2011). Rural school situation in South Africa needs to be cautious about "technology hop". It has been reported in the media that young people, especially those who are at pre-tertiary level of their education, because of their use of the cellphone SMS language, can hardly spell in the English language. Black African South Africans, whose first language is neither English nor Afrikaans, tend to mix words of these two languages when orally communicating in their vernacular languages. These languages were the only two official languages in this country in the past. With Black South Africans, literacy is measured in the medium of English language and this complicates the traditional pedagogic process especially within the context of rural schools. Eskom here in South Africa is trying its best to reach a significant number of our rural communities and therefore the number of schools without electricity is decreasing though slowly. Therefore, parents of learners in these rural schools, together with their SGB's, must consistently ask potential donors to help them with priority learning materials like computers, photocopiers, television sets and radios with or without batteries. Teachers, including those who are in the SGBs of these schools, must never tire of always telling the parents that waiting for the provincial departments of education to provide all their children's needs at these schools, short-sells these children to achieve their maximum in learning outcomes. Village achievers, referred to above, should be wooed instead to always keep their home village schools in mind about all kinds of teaching and learning aids for teachers and learners in these schools.

Rural schools are often in poor repair, poorly equipped and staffed with poorly prepared and poorly paid teachers (Atchoarena \& Gasperini, 2003). The majority of rural school teachers have their houses and rented accommodation at the nearest towns to the schools at which they are employed. Some of these "nearest" towns range from $60 \mathrm{~km}$ to 100 $\mathrm{km}$ away from these schools. Thus, these teachers travel $120 \mathrm{~km}$ to $200 \mathrm{~km}$ every school day of the week. This means they travel from $600 \mathrm{~km}$ to $1000 \mathrm{~km}$ a school week. Add on this the teacher: pupil ratio of 50 to 60 learners to one teacher, plus marking of continuous assessment classroom work. Only those teachers who are forced by their individual circumstances have accommodation at the villages where their schools are. Hence, we have these rural schools, built of mud bricks, no reliable source of water, some with no electricity and telephones. Add on this scenario, teachers who are always looking for teaching posts at schools that are closer to towns because they simply do not see themselves teaching at these rural schools for any length of time.

This situation leaves parents of learners in these schools all on their own with regard to making schools of their children to be places that they can leave their children at for any length of time in their lives. These parents are left with no option but to work with principals of these schools plus those dedicated teachers probably in the level of Senior Management Team (SMT). Ironically, rural schools must have strong and committed School Governing Bodies (SGBs) because they have so much to do to assist their children's teachers in these schools. And because there are no feasible partners that they can plead with to assist the teachers and SBGs to bring these schools closer to the standard of schools close to towns and cities in the country. Finally, there is no form of assistance to bring these schools close to government offices, relevant officials and tertiary institutions with their lecturers in Faculties of Education.

\section{Close to the $1^{\text {st }}$ Quarter of the $21^{\text {st }}$ Century}

We are left with 12 years before we get to 2025, the 1st quarter of this century. The question that we must all answer is: What can be done during these 12 years to advance the cause of all our rural and remote rural schools? We also cannot 
leave out the case of our "Farm schools" in whatever strategies that we must put in place for our rural schools in general.

Learning from our history of the closure of our Colleges of Education, all farm schools must be closed down and their learners must be transported to our closest public schools. There are two advantages for this recommendation. Firstly, the enrolment figures of learners in these schools are low. Secondly, South African national government looks after the commercial farmers on whose farms these schools are located by ensuring that roads (gravel or tarred) to and from these farms are fairly maintained. Hence school transport arranged for these children of all farm workers will not have a problem of reaching these farms in the morning and bringing these children back after school. The same applies to schools that serve children from villages with no proper roads to the schools that they attend except children of the village where the school is built. For example, a school that serves four villages and three of these villages have no proper bus roads that link them to the school. Such schools must be relocated to sites that have roads leading to all of these four villages for purposes of provision of school transport. However, like nutrition programme, school transport that provincial departments of education provide in all our nine provinces has its own human rats. Some of them are among us, education people, individuals or groups of individuals, who misappropriate money that should provide and maintain vehicles that transport children to and from schools. What kinds of mind do these people have? In The Shopsteward, the official magazine of the Congress of South African Trade Unions, (Volume 20. No.3 June/July 2011), Andiswa Kolanisi, Nobantu Vumazonke, Buyiswa Oji, Nomthunzi Foshara, NoEnd Mbayeka, Nosamkelo Lekhoba, Thabisa Ngubo, Nosayinile Mehlwana and Lindelwa Dunga wrote as follows:

Our children need classrooms, toilets that work, water and electricity, fencing, libraries, laboratories and computer centres. These things should not only be for learners at schools in the suburbs. Every child deserves a quality education.

In 2011 these mothers counted eight things that are lacking at their children's schools: (i) not enough classrooms for the children; (ii) no toilets that work; (iii) no water; (iv) no electricity; (v) school buildings that do not have proper fencing; (vi) no libraries; (vii) no laboratories; and (viii) no computer centres. Assuming that these schools have been there since 1995, this says we have been having these schools with us for 18 years of our democratic government. We are left with 12 years before we get to 2025 marking the first quarter of the $21^{\text {st }}$ century and we still have schools such as the ones these mothers describe. A child born this year (2011) will be getting to grade 1 in 2018, grade 8 in 2025 and grade 12 in 2029. Given that the kind of rural schools as described above have been with us for many years before 1994, 50 years and more, it would be unrealistic to expect drastic changes in 19 years. Within this time the government needs to improve conditions to make all rural schools accessible and fully functional. This could be achieved by constructing proper roads, replacing all mud buildings, providing clean water (ground or tap water), providing electricity, bringing in computers, building libraries and laboratories. The government should also attract Mathematics and Science teachers to these schools and provide them with decent accommodation and enough financial allowance to cater for things that they have to do without in these rural environments (the remote and the not remote rurals). Meanwhile, schools in urban and peri-urban areas can, if there are developmental plans in place, use these 19 years to advance classroom technology to match current times.

\section{Conclusion}

Our futuristic imaginations about all schools in this country must be informed by what all of us in the education sector in particular must be determined and committed to see happening in all our schools, not excluding our rural schools. If some of the rural communities and their schools have to be relocated for the sake of ensuring essential progress and development of these schools, so be it. We support that the South African government should budget money to compensate teachers working in remote rural schools with 'inconvenience allowance'. This would incentivise them to work diligently in such schools. If rural schools in Ghana can afford e-readers for their learners, South Africa can also afford same for its rural children? To take along our rural schools beyond the $21^{\text {st }}$ century, we must be bold and courageous enough to accept some of the truth statements articulated by Chambers (1983) as he maintains that poor parents in labour-scarce rural households give their children an urban-biased education and point them towards towns where they exacerbate urban problems. 


\section{References}

Amanor, D. (2011) Kindling Education: David Amanor visits a pilot project in Ghana where technology is giving reading-and teaching-a boost' in Focus on Africa July-September 2011.

ANC (2007) Discussion Document towards a Resolution on Rural Development, Land Reform and Agrarian Change, The National Policy of the ANC, Gallagher Estate.

Atchoarena, D \& Gasperini, L (2003) Education for Rural Development: Towards New Policy Responses. Paris: UNESCO.

Chambers, R. (1983). Rural Development: Putting the Last First. London: Longman.

Chia, R. (2002) in Gray, D. E. (2009). Doing Research in the Real World. London: Sage publications Ltd.

Comprehensive Rural Development Programme (CRDP) website.

Fossil Fuel Foundation of Africa website.

Gray, D. E. (2009). Doing Research in the Real World. Sage publications Ltd. London.

Kolanisi, A. et al. (2011). 'A Working Class Mother's Cry' in The Shopsteward, Vol. 20. No. 3. Leadership. Edition 317 July 2011.

Makgoba. M. W. (ed) (1999). African Renaissance. Cape Town.

News 24.com 2010-10-28

Ornstein, A. C. (1978). Education and social inquiry. F. E. Peacock publishers.

Reason, P. \& Torbert, W. (2001) in Denzin, N. K. and Lincoln, Y. S. (2005). The Sage Handbook of Qualitative Research. London.

Stevens, E. \& Wood, G. H. (1992). Justice, Ideology and Education. New York.

Sowetan 25 June 2012

Van der Berg, S. (2010) Poverty and education. The Institute For Educational planning. Eugene. Delacroix, Paris, France.

WWMP media. February 17, 2011 